\title{
CONSERVACIÓN Y GESTIÓN DEL PATRIMONIO ARQUEOLÓGICO: UN DESAFío PARA LA ARQUEOLOGÍA DEL NOR-OESTE ARGENTINO
}

\author{
Jorge A. Sosa
}

\begin{abstract}
Sumilla:
El reciente avance de los procesos de liberalización y reestructuración económico-estatal desencadenados en varios paises de Latinoamérica, en el marco de una politica económica neo-liberal, han provocado una serie de efectos negativos, en forma directa o indirecta, sobre el patrimonio arqueologico. Por otra parte, los intentos históricos tendientes a poner algún tipo de freno a esta situación, no han demostrado ser muy eficaces al respecto.

En este articulc se toman como ejes de trabajo interrelacionados; por un lado, la necesidad de generar un replanteo intermo sobre el rol del arqueólogo y su campo de estudio en la sociedad y, por otro lado, se propone abandonar el tradicional tratamiento del patrimonio como elemento meramente simbólico-cultural, a cambio de una visión que lo contemple como recurso polivalente que posee valor cultural, educativo y económico; a fin de lograr una resignificación de los elementos patrimoniales que lleve a una protección más eficiente de los mismos, a la vez que su proyección a la sociedad en forma efectiva.
\end{abstract}

\section{Abstract:}

The recent liberalization and economicre-estructuration processes in various Latin-American countries have a directly and indirectly negative effects over the archaeological heritage. This paper tries to reformulate the archaeologists work and their field of study within the society; on the other side it proposes to change the traditional heritage treatment, a merely simbolic and cultural element, to a multicomponent resource. This point of view will help to protect the archaeological henitage in an efficient way.

\section{INTRODUCCIÓN}

El reciente avance de los procesos de liberalización y reestructuración económica desencadenados en nuestro país y en varios de nuestros vecinos de Latinoamérica, en el marco de una política económica neo-liberal (Mattos, 1996), han provocado una serie de efectos negativos, en forma directa o indirecta, sobre el patrimonio arqueológico. La reforma del Estado ha impuesto recortes a la asistencia económica de áreas que no son consideradas eficientes, midiéndose la eficiencia en términos de rédito económico. Una de estas áreas ha sido la de las investigaciones humanísticas.

Si bien declaraciones oficiales predican la importancia que le otorgan al tema de la educación, como un factor para el cambio y el desarrollo convergente, en realidad dicha importancia es mediatizada por el marco que proponen los modelos de crecimiento endógeno. surgidos en el mismo corazón del pensamiento neoclásico, y que se traduce en el apoyo económico a ciertas áreas del conocimiento, relacionadas fundamentalmente con el sistema productivo y la necesidad de "elevar el capital humano" (Luckas, 1988).
Ante esta tendencia macro-económica, de amplia aceptación y difusión por parte de las economías centrales y que es dirigida por el Estado, la investigación arqueológica se ha visto afectada por la falta de recursos económicos que la financien, indispensables dadas sus características, además de haber estado siempre ligada a la subvención estatal y a la cooperación técnica internacional.

Este proceso ha provocado un doble impacto sobre el patrimonio arqueológico, ya que, por un lado, se ven limitadas las posibilidades de conocimiento sobre él, al recortarse los fondos para la investigación; mientras que, por otro lado, al ser percibido el patrimonio como algo sin importancia, puede ser afectado impunemente, aún existiendo legislación en contra, por cualquier emprendimiento económico que prometa réditos económicos y políticos a corto plazo.

Esta situación plantea un desafío a la comunidad arqueológica: aceptar las nuevas reglas de juego y plantear una competencia interna en la que sólo sobrevivan los más aptos, o tratar de recuperar el espacio y protagonismo perdido como actores sociales,

Jorge A. Sosa. Licenciado en Arqueología. Museo Eınografico. Facultad de Filosofía y Letras. Universidad de Buenos Aires.

E-mail: jsosa@ethnik.filo.uba.ar 
mediante la reformulación y definición explícita del rol que nos compete, no sólo para justificar nuestra existencia ante nosotros mismos, sino también ante el resto de la sociedad.

Tomando como guía de trabajo la segunda de las propuestas antes señaladas, en este artículo se plantean como ejes de trabajo interrelacionados, primero, la necesidad de generar un replanteo interno sobre el rol del arqueólogo y su campo de estudio en la sociedad; y segundo, se propone abandonar el tradicional tratamiento de patrimonio como elemento meramente simbólico-cultural, a cambio de una visión que contemple al patrimonio como recurso polivalente que posee al mismo tiempo un valor cultural, educativo y económico, modificando el significado de los elementos patrimoniales y contribuyendo así a una más efíciente protección de los mismos. En este sentido se propone, como estrategia de trabajo, intentar la integración con sectores críticos de la economía nacional, como el turismo, pero de forma tal que se asegure la generación de recursos para la conservación del patrimonio. Para ello hay que hacer un trabajo integral que contemple criterios conservacionistas provenientes de la disciplina antropológica y arqueológica, coherente con una propuesta de desarrollo sustentable.

Si bien creo que los lineamientos básicos expresados hásta aquí son extensibles al Noroeste Argentino (NOA) en general, también reconozco la especificidad y complejidad de cada escenario dentro del NOA, por lo que en este trabajo se plantea como escenario especifico de referencia el Valle de Yokavil o Santa María, en su porción correspondiente al territorio de la provincia de Catamarca.

\section{ESTADO DE LA CUESTIÓN EN EL VALLE DE SANTA MARIA}

El Valle de Santa María, comprendido entre las provincias de Catamarca (departamento de Santa María), Tucumán (departamento de Tafí del Valle) y Salta (departamento de Cafayate), ha sido uno de los principales escenarios del desarrollo de la disciplina arqueológica desde fines del siglo XIX. Investigadores de diferentes nacionalidades han demostrado la gran riqueza patrimonial que este valle atesora y que se concentra en sus $100 \mathrm{~km}$ de longitud. Los numerosos sitios en él ubicados revelan que el valle ha sido intensamente ocupado, por lo menos desde principios de la era cristiana, hasta la invasión de los españoles. Sin embargo, los sitios que más han llamado la atención son aquellos pertenecientes a los últimos siglos de ocupación prehispánica (siglos IX al XVI), conocidos con el nombre de "santamarianos e incaicos", los cuales se destacan por su magnitud arquitectónica.
Debido a la constante falta de apoyo económi$c o$, la gran mayoría de estos sitios no cuenta con sistemas de protección, ni con presupuestos que permitan la realización de las investigaciones científicas de largo plazo que requieren. Por estas causas, este patrimonio actualmente se ve seriamente amenazado por procesos de destrucción naturales y antrópicos, sin contar con herramientas técnico-económicas que permitan revertir este proceso a corto ni largo plazo.

Paralelamente, y como consecuencia del incremento sostenido que viene experimentando la actividad turística en nuestro país (El Mensajero, 1997:32; Report, 1997:26), tanto en el mercado tradicional como en las actividades denominadas alternativas, el noroeste, en general, ha comenzado a funcionar como un incipiente polo de atracción, basado fundamentalmente en sus bellezas paisajísticas y en sus recursos culturales y humanos, elementos clásicos ya del "Producto Noroeste" pero que adquieren nueva fuerza con el auge del llamado turismo verde. Ante esta nueva tendencia, ya no son pocas las agencias de viajes y prestadores que ofrecen, entre sus paquetes, visitas a lugares de interés patrimonial, tanto antropológico como paleontológico, sin contar, muchas de ellas, con la colaboración de personal idóneo para la realización y diseño de tales visitas.

Por parte del gobierno nacional no existe control al respecto y las pocas propuestas existentes, como por ejemplo la realizada por el senador Antonio Cafiero (Ralli, 1996:22), han encontrado una fuerte resistencia entre los agentes de viaje relacionados a la política.

Entre los recursos culturales que las provincias han querido incluir dentro de su oferta turística se encuentran los sitios arqueológicos, pero sin tomar en cuenta, en la gran mayoría de los casos, si los mismos se encuentran preparados o no para recibir visitantes, situación que, de hecho, se viene registrando desde décadas atrás. Asimismo, tampoco se toma en cuenta el tipo de condicionamientos que deberían regir la realización de visitas a los mismos. La aventura mercantil realizada en el sitio de Quilmes, departamento de Tafí del Valle, Tucumán, es más que elocuente.

Ante esta situación, uno parecería encontrarse ante un dilema de diff́cil solución, ¿qué hacer?; $¿$ prohibir el acceso a los sitios a posibles visitantes interesados en conocer el pasado, y encomendarse a Dios para que el tiempo y los delincuentes se apiaden de los sitios? o ¿permitir el acceso a todo el público en aras de conseguir ganancias a costa de una aceleración de la depredación y destrucción de los sitios?.

En este trabajo se plantea una alternativa de solución a este dilema: la formulación de una estrate. 
gia de resignificación, promoción y difusión del patrimonio cultural, bajo la supervisión de las unidades académicas y/o científicas correspondientes a cada área de interés en particular, dicha estrategia se ha denominado Turismo Arqueológico o Arqueoturismo.

\section{ARQUEOLOGÍA Y SOCIEDAD}

Lamentablemente, durante décadas, tal vez como herencia o maldición de las formulaciones de los años 30 y 40 (Pérez Gollán, 1989), la investigación arqueológica siguió por caminos que la alejaron del contacto con el resto de la sociedad, provocando de esta manera que el circuito que debe existir entre comunidad científica y sociedad a través de la difusión de los conocimientos, no cerrara.

En virtud de ello, no debe sorprender a nadie que hoy en día la mayoría de la gente sólo recuerde nombres como Diaguita, Toba, Guaraní o Mapuche, como sinónimo de indígena, pero que no tenga la más mínima idea de lo que ello significa, o del universo que se csconde detrás de cada una de estas palabras. En la sociedad argentina, la arqueología se encuentra conceptualizada como una ciencia ajena a nuestro país, que sólo puede desarrollarse en el exterior, ya sea en Perú, Centroamérica, Europa o el cercano Oriente y esto es, en parte, responsabilidad de todos los profesionales ligados a la disciplina (entre los que me incluyo), al no haber dedicado, por lo menos desde 1983, el mismo esfuerzo que se aplica a la investigación, a la divulgación de nuestros conocimientos, a través de la búsqueda y/o creación de canales adecuados, y la transformación del lenguaje académico en uno ameno y con significados asequibles a todos.

Creo que esta situación nos obliga a sostener, de una vez por todas, un profundo autocuestionamiento sobre el por qué de esta aparente crisis de identidad, que nos hace estudiosos de la sociedad, presente o pasada, pero que nos coloca a un costado de la misma. Coincido en esto con el colega José Pérez, cuando sostenía que: "Es imperioso que como antropólogos, podamos imaginar el lugar que deseamos ocupar en la sociedad civil -y también en la política- y hallar los medios para lograrlo" (Pérez Gollán, 1989:88). En este sentido, creo que la disyuntiva es cada vez más clara: o nos subimos al carro del discurso neo-positivista importado y continuamos por transformarnos en tecnócratas del pasado, mediante el ejercicio de una ciencia de la "cosa" en aras de ajustarnos a un discurso cientificista de monismo metodologico baconiano, o nos planteamos la tarea de construir una disciplina con rigor científico, pero cuyo objetivo final sea, además de la generación de conocimientos, la divulgación e inserción de los mismos en la sociedad.
Ante la situación antes señalada de hermetismo académico no es extraño percibir, por parte de algunos sectores de la sociedad, un clima de indiferencia y, en algunos casos (como señalara González, 1991:33), de desprecio hacia las producciones prehispánicas locales. Si bien, por lo general, esto ocurre en aquellos sectores de la sociedad lejanos tanto espacial como ancestral y culturalmente a los sitios arqueológicos, la situación no parece muy diferente a la de aquellas sociedades que conviven con el marco natural-arqueológico. Allí, las raíces parecen estar cortadas, ya que se evidencia una confusa desconexión cultural fruto, tal vez, del reemplazo poblacional y el aculturamiento histórico que incitó al olvido y menosprecio del origen indígena o de todo aquello relacionado con él. La existencia de los sitios es vista con muy poca curiosidad y, en algunos casos, con total indiferencia. Merced a estas actitudes, algunos sitios, por lo general los más distantes, han podido escapar a la destrucción causada por el hombre, pero en otros casos, estas mismas actitudes se han manifestado o provocado componamientos contrarios al interés de protección. Es así que, al carecer los sitios de valor alguno, culturalmente hablando, los mismos sólo son vistos en su dimensión material y, por lo tanto, sólo considerados desde una perspectiva utilitarista. Así, las pircas arqueológicas son desmanteladas para levantar nuevas paredes o corrales; los petroglifos son canteados para ser usados como detalles decorativos; o los cementerios son huaqueados con la más infame y macabra de las intenciones: vender el ajuar funerario.

Para colmo de males, esta situación de abandono espontáneo se complica aún más cuando desde las esferas de decisión política locales (léase por ejemplo Municipalidad), se construye un discurso "modernizante", el clásico "mirar hacia el futuro", que fomenta la asimilación de los nuevos valores de la sociedad de consumo, demostrando un desprecio implícito o explícito por la herencia prehispánica y, a veces, también hispánica (Magadán, 1988). El afán de modernización o renovación, hace cundir el menosprecio por las manifestaciones del pasado que no se ajusten al estilo de vida que se tipifica como moderno. Bajo los efectos de esta fiebre de modemidad y sin capacitación adecuada, los habitantes de una población no pueden medir totalmente las consecuencias de su accionar destructivo hacia el patrimonio, el cual realizan bajo la indiferencia o complicidad de los gobiernos locales (OEA, 1973a).

Pa a completar el cuadro de desaliento, el estado de miseria y pobreza que padecen las poblaciones marginadas de gran parte del noroeste vallisto, fruto de los procesos de divergencia económica entre el centro y la periferia del país, es el elemento de presión fundamental para que las mismas no duden en encarar cualquier tipo de actividad que ayude a paliar su actual situación de desaliento y marginación. 
La combinación de estos cuatro factores, hermetismo académico, intereses mercantilistas, subvaloración cultural y divergencia económica, han producido un cuadro de situación en donde los mayores perjudicados son las sociedades locales y el patrimonio arqueo-histórico-cultural. ¿Qué podemos hacer ante esto?.

\section{HACIA UNA DEFINICIÓNDELAGESTIÓNDEL PATRIMONIOCULTURAL}

Una vez reconocidos los factores que afectan la integridad del patrimonio, parece lógico sostener que sólo podrá lograrse algún resultado positivo evaluando y promoviendo el desarrollo de cada uno de éstos, como un todo armónico, es decir, la solución a nuestra preocupación sólo podrá provenir del control, interjuego y modificación conjunta que podamos hacer de estos factores. Para ello, será necesario plantearse algunas preguntas de fondo que nos ayuden a delinear el rumbo a seguir, en el intento por superar los problemas antes citados. Algunas de las preguntas primarias que deseo formular aquí son: ¿Qué es el patrimonio arqueológico?, ¿Quién lo protege?, ¿Cuáles son los mecanismos de protección y control del patrimonio?, ¿Quién y cómo se gestiona el patrimonio?.

\section{El Patrimonio como recurso:}

El primer punto a señalar en este sentido, consiste en reconocer y definir la naturaleza del patrimonio arqueológico. Si bien es innegable el valor de los aportes de otros colegas como García Canclini (1989), Delfino y Rodriguez (1989), Lumbreras (1989), Madrazzo (1989), Pérez Gollán (1991), y Bonfil Batalla (1994), al resaltar la importancia de reconocer el fuerte lazo del concepto de patrimonio, con el de construcción social e identidad, a los fines últimos de este trabajo, he preferido enfatizar aquí el tratamiento del tema del patrimonio desde otra óptica.

Desde mi punto de vista, el patrimonio es un recurso cultural, frágil, no renovable y específico al espacio que ocupa. Considerar al patrimonio como un recurso permite gozar de ciertas ventajas. En primer lugar, conlleva a reconocer además de su valor cultural, su valor económico $\mathrm{y}$, por lo tanto, su posibilidad de incorporación al sistema social circundante, pero con la consecuente necesidad de valoración y aceptación de la responsabilidad que implica su gestión. Considerar al patrimonio como un recurso conlleva, además, a reconocer que las medidas adecuadas para su preservación y protección no sólo guardan relación con los planes de desarrollo locales, sino que deben formar parte de ellos.

Por otra parte, resaltar al patrimonio como recurso resulta de gran ayuda para una de las tareas primigenias de todo ésto, que es la justificación de la conservación del patrimonio. Ésta es una de las cuestiones fundamentales a resolver, ya que del grado de efectividad con que logremos contagiar nuestra valoración sobre la importancia del patrimonio dependerá la mayor coparticipación que se logre entre los intereses académicos y los de la comunidad y de ella, a la vez, resultará la efectividad o el fracaso de las acciones de conservación: "Si por el contrario, el patrimonio es considerado también algo presente y no ajeno a la experiencia vital de grupos y personas, tendrá mayores posibilidades de ser socialmente apreciado y defendido" (Rosas Mantecón, 1994: 39). Para la realización de esta tarea de contagio, creo que es esencial valerse de una batería de argumentos, entre los cuales, el concepto de recurso es de suma utilidad.

El patrimonio arqueológico es aquí concebido como una producción cultural irrepetible y finita, por cuanto sus creadores ya no existen y, por lo tanto, no puede seguir creciendo ni reproducirse. A ésto debe sumarse el hecho que cada componente del patrimonio es único en cuanto a su disposición interna, por más que existan patrones o pautas compartidas, y también en cuanto a su disposición y posición en el espacio y el paisaje. Su lugar en el mundo no es fruto del azar, sino que obedeció a múltiples causales que, por lo general, entrelazaban diferentes esferas de la producción y reproducción social. Es por ello que cada uno de los asentamientos, sitios, yacimientos o como se le quiera llamar a los componentes del patrimonio, son aquí vistos como únicos y específicos, ya que cada uno de ellos juega un papel irreemplazable en el intento por explicar y revalorizar a las sociedades que allí vivieron.

Para promover el estudio y revalorización del patrimonio es imprescindible asegurar la supervivencia de sus componentes, lo cual sólo es posible mediante el desarrollo de políticas de protección de los mismos. Ésto nos remite a la siguiente interrogante: ¿Quién y cómo se gestiona la protección de los sitios?.

\section{FACTORESDE LAGESTIÓNDELPATRIMONIO CULTURAL}

\section{a) Legislación}

Contrariamente a la visión clásica que vincula protección con la vigencia exclusiva de sistemas represivos, aquí se pondera el uso de un mecanismo mixto, en donde la concientización, es decir, puesta en valor ante la sociedad local y nacional y la legislación, trabajen como dos herramientas complementarias e irreductibles una a la otra. Desde ya, el papel de la legislación juega aquí un papel preponderante, por cuanto constituye el marco fundante de advertencia, prevención y castigo contra las actividades puramente delictivas, en tanto la destrucción del patrimonio se realiza con culpa y dolo. Pero debe reconocerse que la efectividad de la misma sólo 
puede lograrse mediante la aplicación de medidas conjuntas interprovinciales, provinciales nacionales, de modo tal que permitan establecer una red de seguridad que no logre ser burlada por cuestiones de límites territoriales provinciales. Es aquí donde se necesita la colaboración de los cuerpos legislativos locales para la realización de acuerdos entre las provincias y entre ellas y el Estado, que comprendan y neutralicen los circuitos de tráfico delictivos. En este sentido, la creación de una Comisión de Enlace, aparece como una respuesta corporativa necesaria para promover y desarrollar tales interrelaciones.

Por otra parte, si bien se reconoce la dificultad en la aplicación del conjunto de leyes existentes, ya sea por . inoperabilidad de las mismas o por contraposición con otras existentes, derivadas de otro tipo de intereses de desarrollo (?) económico, nacional o provincial, se enfatiza aquí la necesidad de bregar por el cumplimiento de las mismas y su observación e inclusión en todo proyecto que se pretenda realizar, como así también colaborar, desde el ámbito científico, en la elaboración de propuestas basadas en la experiencia personal de cada investigador.

\section{b) Concientización y sustento}

Conjuntamente con el fortalecimiento $y$ expansión de los sistemas de protección legal, debe trabajarse intensamente el tema de la concientización. Por concientización se entiende el trabajo de divulgación y extensión de los conocimientos cientúficos o académicos, por parte de la comunidad universitaria que realiza investigaciones en el marco territorial que comprende el patrimonio, hacia la comunidad local, con el asesoramiento de personal idóneo en tareas de ese tipo, cuando sea necesario. Las metodologías han de variar según los soportes físicos disponibles para dichas actividades, tales como aulas de escuelas, salones de exposición, casas de cultura, medios de comunicación audio-visual, etc. También dependen de los recursos económicos al alcance, los cuales podrían o deberían provenir de un aporte mixto entre gobierno local y las unidades académicas actuantes; para ello sería necesario que los proyectos de investigación estén armados de forma tal que asignen una parte del presupuesto a tareas de difusión.

Los efectos que ésto puede tener a corto y largo plazo son más que alentadores para el futuro de la conservación de los sitios arqueológicos. Es conocido el hecho que muchos pobladores locales conviven durante gran parte de su vida en contacto directo con restos arqueológicos sin siquiera saberlo, por lo cual su conducta de agresión hacia el patrimonio se efectúa sin dolo, por lo que no merece castigo, sino acciones que eliminen la simple ignorancia. También existe el caso de personas que conocen el origen de los restos pero que ignoran su valor; para ellos sólo se trata de cosas viejas que algunos visitan y otros escarban en busca de algún "souvenir". También hay casos de personas que conocen el valor comercial de algunos de los objetos que pueden recuperar de los sitios y no dudan en realizar excavaciones en busca de ellos, para así paliar mínimamente situaciones apremiantes en su condicióı de pobreza.

Para el primer caso se piensa en la concientización como una forma de contrarrestar el efecto negativo que implica el ejercicio de la ignorancia, sobre las potencialidades de desarrollo (científicas y económicas) que encierra el patrimonio.

Pero en realidad, son dos tipos de acciones complementarias las que son requeridas en este sentido. Por un lado, el trabajo de difusión y extensión del conocimiento adquirido ya mencionado. Pero por otro lado, es necesario dar sustento físico a la tarea de concientización, mediante una reconversión del patrimonio de elemento pasivo, económica y socialmente hablando, a elemento activo en sí mismo y dinamizador micro-económico. La idea es buscar la forma de poder generar recursos económicos lícitos y sustentables en el tiempo, mediante el manejo de los recursos patrimoniales. Sin duda que para ello será necesario, además, discutir la escala temporal en el marco de estudios de impacto y sustentabilidad.

Una de las actividades posibles, con antecedentes cercanos, tanto geográficos como temporales, positivos y negativos (Schávelzon, 1989-1990), es el turismo. Desde el punto de vista antropológico, la visión romántica del turismo como la industria sin chimeneas se encuentra totalmente descartada. Esta actividad de servicios es tan perturbadora como cualquiera, no sólo por las modificaciones en infraestructura que genera, sino por los procesos de relacionamiento cultural que ejerce y que, muchas veces, se convierten en fenómenos de agresión sobre las poblaciones anfitrionas y el medio natural. Sin embargo, hay que reconocer que, en gran parte. el origen de esta situación de perturbación se halla en el propio proceso de génesis y ejecución de las propuestas turísticas (Carvajal, 1992).

Para que el desarrollo de actividades turísticas pueda estar dentro del espíritu aquí propuesto y los objetivos de concientización y conservación sean cumplidos, es necesario que se incluyan atractivos culturales locales sobre los cuales, en la gran mayoria de los casos, ya existe relevamiento turístico. Esta integralidad en el manej j de los recursos locales y su potenciación para el turismo abre la posibilidad de que los habitantes del lugar puedan obtener algún beneficio económico directo como, por ejemplo, a través de la exhibición y venta de su producción artesanal. No se trata aquí de fomentar un "turismo de rodillas" (Marini, 1979), orientado a mostrar poblaciones mendicantes de ayuda, de lo que se trata es de impulsar la formación de canales de acceso que faciliten a los pobladores vecinos acudir a los sitios de interés arqueologico, de modo que también 
ellos tengan la oportunidad de mostrar su producción artesanal y evitar así la intermediación que funciona en las ciudades próximas, como Tafi del Valle o Cafayate (por mencionar sólo un par).

A lo que apunta la propuesta de ambas acciones es a impulsar una resignificación del patrimonio y a la búsqueda de un sustento material que cimente dicha resignificación, ya que, de lo contrario, se vería expuesta a quedar diluida por el ejercicio diario y real de las circunstancias socioeconómicas del medio de vida. Lo que se persigue con esta acción es estimular la formación de un cuerpo social local, interesado en la conservación del patrimonio y en mejores condiciones para controlarlo y mantenerlo. Este intento de resignificación implica la necesidad de desterrar la analogía entre patrimonio y estética, monumentalismo y estanqueidad. Hay que acercar lo lejano y movilizar lo estático. Para ello, es necesario trabajar en la recuperación histórica del patrimonio, otorgándole vida y sentido ante la sociedad e incorporándolo al proceso de socialización de la población.

\section{c) La propiedad del patrimonio}

Otro punto de importancia que permite la protección efectiva del patrimonio está íntimamente ligado a la propiedad de la tierra donde están los sitios arqueológicos. En líneas generales, la legislación de cada provincia declara la urilidad pública de los yacimientos, sitios y/o materiales arqueológicos que se encuentran en sus territorios y declara a la provineia como sujeto patrimonial ${ }^{2}$. Sin embargo, para superar la instancia declarativa y para que esta fórmula legal se vuelva operativa, debería ser acompañada del acto de posesión efectiva de los terrenos en cuestión.

Para esto se requiere realizar acciones de expropiación, aunque hoy en día los gobiemos prefieran no llevarlas a cabo; en parte, por problemas presupuestarios y porque acciones de ese tipo no ofrecen rentabilidad. Por lo general, los entes de gobierno tienden a desestimar el tema patrimonial, ya sea éste natural o cultural, debido a que no se lo identifica con los problemas inmediatos o urgentes del país: carencia de viviendas, desempleo, problemas de sanidad, etc. Si bien los problemas de patrimonio son considerados como atinentes a la calidad de vida, la idea es que sólo hay que acercárseles una vez solucionados los problemas "básicos". Esta actitud en realidad desconoce u oculta el hecho de que el patrimonio natural y cultural es factor y parte de la crisis misma (Gligo, 1987).

En este sentido, creemos que para optimizar el desarrollo de una acción concientizadora como la que antes se propuso, la comunidad académica debería contemplar la posibilidad de acercar también su discurso hacia las esferas de poder y decisión política (González, 1984). Tal vez, mediante la comisión de enlace antes sugerida, se pueda reforzar su presencia y modificar la imagen errónea que existe en las esferas de decisión sobre el contenido y la importancia del patrimonio.

\section{d) EJ registro del patrimonio}

Al sra bien, no podemos abandonar el tema de la protección del patrimonio sin reconocer que, para que todo lo expresado con anterioridad tenga alguna validez es necesario, como paso previo fundamental, poder evaluar la magnitud fáctica del patrimonio en cuestión. Es necesario contar con un panorama completo de la situación, extensión y estado del patrimonio de la región. Esta información, que resulta imprescindible para fundamentar cualquier solicitud de financiamiento u otro apoyo, no se posee. Así como los bienes muebles (Champin, 1996), también es muy importante registrar los bienes inmuebles (OEA, 1973b) como los sitios arqueológicos, ya que sin un inventario de la situación y estado de los mismos en un tiempo dado, no se puede evaluar la evolución de dichos bienes y, por lo tanto, se pierde el control sobre los procesos que actúan en ellos, además que no se puede demostrar, por falta de antecedentes, si los mismos sufren algún deterioro parcial o total.

En este sentido, será necesario fomentar estrategias de investigación tendientes a desarrollar ctapas exploratorias del territorio, para poder recolectar información: coordenadas geográficas, extensión, accesibilidad, propiedad de las tierras afectadas, aproximación temporal, etc. De esta manera se conformaría una Base de Datos del Patrimonio Arqueológico (B.D.P.A.) electrónica o informatizada (Sosa, 1997 ms.). Este tipo de tratamiento de la información permite una rápida difusión y flexibilidad de trabajo, flexibilidad imprescindible dado el carácter acumulativo que tendría la misma, en la medida que las investigaciones de campo progresen. Al mismo tiempo, esto abre la posibilidad de incorporar el universo arqueologico a las nuevas técnicas de control y estudio del patrimonio, ligadas a las nuevas tecnologías que lentamente se expanden en el mundo. Un ejemplo de las mismas es el uso de los sistemas de información geografica, los cuales, mediante la nueva generación de satélites con mayores resoluciones espectrales y espaciales, brindan resultados más precisos que sus predecesores. Vale la pena destacar que estas tecnologías, antes carísimas, se encuentran cada vez más al alcance de las unidades académicas.

Como segunda parte de esta estrategia, sería necesario desarrollar mecanismos sistemáticos de monitoreo, posiblemente por muestreo, capaces de detectar y medir los cambios que se efectúen en el patrimonio, ya sean éstos de origen natural o antrópico, a lo largo del tiempo. Sólo la adecuada percepción de la evolución del patrimonio permitirá el desarrollo de una planificación capaz de compatibilizar los intereses en pugna, tanto a corto como a largo plazo. 
En síntesis, si lo que se pretende es salvaguardar el patrimonio cultural de una región, se deberá trazar una estrategia conjunta. Ésta debe partir de la evaluación local e individualización de los factores actuantes en el deterioro patrimonial, como los delineados en esta sección, y ser capaz de generar una política de desarrollo consensual entre los intereses locales y los académicos, y entre los públicos y los particulares; es decir, ser sustentable a largo plazo, teniendo en cuenta conceptos y recursos temporales, tecnologicos y financieros. Es necesario destacar que, si en última instancia, lo que los gobiernos locales pretenden es mejorar la calidad de vida de sus comunidades, deben incluir en el marco de sus políticas de desarrollo, la evaluación y salvaguarda del patrimonio, ya que, como se ha expresado, es también una parte importante del ambiente.

\section{UNAPROPUESTADEGESTIÓNDEL PATRIMONIO: TURISMOARQUEOLÓGICO}

En la siguiente sección, se tratará de exponer un ejemplo del proyecto "Turismo Arqueológico", el cual fue pensado como un intento de solución al grave problema del deterioro que están sufriendo actualmente los sitios arqueológicos del Valle de Santa María, en su sección comprendida dentro del territorio de la provincia de Catamarca. Esta delimitación no significa que las otras secciones del valle, comprendidas por otras provincias, se hallen en mejores condiciones; tan sólo obedece a un recorte operativo, basado en la delimitación del actual territorio.

Esta propuesta recoge las inquietudes previamente señaladas y plantea la posibilidad de realizar actividades turísticas de bajo impacto, como una forma de lograr los objetivos de salvaguarda, difusión, resignificación y autosustento del patrimonio arqueológico. La misma ha sido pensada para su aplicación a ciertos sitios o yacimientos con arquitectura y/o con representaciones artísticas a cielo abierto.

Los antecedentes de la relación entre Turismo y Arqueología son desalentadores. En todas partes del mundo son numerosos los ejemplos de los daños causados por los visitantes a los sitios arqueológicos (Schavelzon, 1990; Report, 1995a, 1995b; Viajero VIP, 1995). En nuestro país, las propuestas de desarrollar la difusión y conservación arqueológica con el de:arrollo turístico reconoce antecedentes temporalmente lejanos en los trabajos de González (1954: 76, y década de 1960, com. pers.). Paralelamente, la práctica de visitas a sitios arqueológicos es algo que viene efectuándose desde décadas atrás. El ejemplo más conocido y con más antigüedad al respecto, es el caso del Pucará de Tilcara, a pesar de que existen algunas opiniones en su contra: "Los sitios prehispánicos del Noroeste no sirven aún como atractivo para el turismo. Sin embargo, desde hace unos años se propone esta actividad como una explotación importante para mejorar la economía regional. A los empresarios y los funcionarios de turismo, los visitantes les importan como consumidores" (Macadán, 1989: 66). Por otro lado, ya han existido algunas sugerencias respecto al desarrollo del turismo arqueológico como una estrategia de difusión y conservación.

En este sentido, podría decirse que no tiene nada de original, ni de alentador, la propuesta de organizar visitas a sitios arqueologicos; sin embargo, debe decirse que la diferencia aquí consiste no sólo en enunciar su posibilidad, sino en ser partícipe activo del proceso de puesta en valor, mediante el diseño de la actividad turística, tomando como punto de partida las normas esenciales de conservación del patrimonio. Es necesario elaborar programas a la medida de cada lugar de visita, con contenidos basados en los datos científicos, respetuosos de las leyes vigentes, tanto a nivel nacional y provincial, sobre patrimonio y actividades turísticas.

El uso de los términos Arqueoturismo o Turismo Arqueológico, no significa sólo tomar como puntos de visita lugares arqueológicos, sino que hace referencia a una forma especial de desarrollar una actividad turística en este tipo de medio frágil y no renovable, en un marco de excelencia en cuanto a la información que se brinda, por cuanto la misma debe estar a cargo de personal especializado (arqueólogos y/o antropólogos). Asimismo, incluye criterios de más largo alcance que involucran métodos que se aplican para la visita de los sitios, al privilegiar la integridad y preservación del patrimonio antes que la rentabilidad inmediata. Es decir, que la práctica de 'i urismo Arqueológico conlleva la responsabilidad de realizar visitas controladas a sitios arqueológicos, no sólo desde el punto de vista informativo, sino también desde el punto de vista físico.

Para ello, se reconoce que es fundamental contar con una infraestructura mínima, así como con un corpus de conocimiento acabado sobre lo que se quiere mostrar y un sistema base de control. Esta concepción obliga a diferenciar dos tipos de áreas o espacios de funcionamiento: una de concentración de funciones y otra de observación o interés. Dichas áreas, si bien complementarias, deberían estar lo suficientemente alejadas entre sí (a diferencia de lo que sucede en el caso de Quilmes, en la Provincia de Tucumán), a fin de reducir el riesgo de perturbación de la primera hacia la segunda, pero lo suficientemente próximas como para poder alcanzar a pie, en un tiempo razonable, el área de interés, debido a la perturbación que provocaría la existencia de caminos para vehículos en sitios arqueológicos.

El área de concentración es un espacio en donde se encuentran aquellos aparatos administrativos que permiten controlar el flujo de visitantes, así también, les brinda el soporte de servicios deseable (baños, lugar de sombra, descanso y refrigerio, elementos de interpretación 
del sitio, etc.). Este tipo de área sería uno de los elementos a incorporar en la totalidad de los casos de los sitios correspondientes al territorio catamarqueño, por lo que será menester, por el costo de inversión que supone, tratar de buscar las políticas adecuadas para la promoción de la instalación de las mismas.

El segundo tipo de área o área de interés, consiste en un sector de la zona de extensión de los restos arqueológicos, la cual debería gozar de ciertas características físicas básicas para su visita, así también, deberá haber sido previamente reconocida y evaluada su importancia patrimonial, a base de estudios científicos anteriores, que justifique su apertura al público.

Ambas áreas deberían funcionar dentro de un área mayor que las comprendiese, la que se podría llamar área de reserva arqueológica; esta funcionaría como un área de amortiguación entre el sitio o zona arqueológica y el resto del paisaje circundante. La extensión de la misma dependerá de muchos factores, entre ellos la topografía del lugar, o el valor o uso actual de los terrenos comprendidos, pero que debería conformar un cinturón alrededor de la zona arqueológica de no menos de 200 metros de ancho.

Uno de los requisitos físicos mínimos consiste en la existencia de un camino o senda que permita el acceso al sitio de interés por un solo punto, a fin de facilitar el control de ingresos. Al interior del perímetro del sitio en cuestión, debería instalarse un sistema de señalización que indique el eje de desplazamiento a seguir, y que a la vez, restrinja el libre desplazamiento de personas. La presencia de un guía especializado contribuiría también en el control del recorrido señalado por él.

Dichos requisitos deberán ser informados a los visitantes con anterioridad a la visita, a fin de evitar malos entendidos, lo cual permitirá adoptar las medidas que se estimen convenientes, en caso de que la conducta de algunas personas pudieran poner en peligro la integridad del patrimonio.

Para evitar los problemas de desechos, se debería establecer la prohibición de ingresar a las áreas de interés con alimentos o bebidas de cualquier tipo, que pudieran originar residuos sólidos o líquidos, así también, establecer la prohibición de arrojar residuos de cualquier tipo en el interior del área de interés. La existencia de infraestructura sanitaria en el área de interés, o recorrido, si bien deseable, no es imprescindible en una primera etapa de desarrollo, hasta que el itinerario incluya otro tipo de atractivos culturales que cuenten con esta infraestructura básica.

La guardianía del área de concentración deberá ser permanente para evitar el ingreso de visitantes no autorizados. Sería deseable que las autorizaciones pudiesen ser controladas por una autoridad local dependiente de la Dirección de Antropología provincial, o bien por parte de algún ente local particular de reconocida solvencia en la actividad.

Por otra parte, el ingreso de visitantes deberá tener algún tipo de utilidad económica que pueda ser reinvertida en el mantenimiento del patrimonio que se explota. Dicha utilidad, si bien podría formar parte de un fondo común, debería ingresar al mismo luego de su registro por unidad de procedencia (cada sitio detallado), a fin de poder monitorear y evaluar el interés despertado por las diferentes opciones expuestas.

La puesta en marcha de un proyecto de este tipo, que necesariamente debería estar en el marco legal de una estructura formal de prestación de servicios turísticos, podría ser considerada como una prueba piloto, que esté sujeta a evaluación, para verificar el grado de aproximación a los objetivos propuestos en el proyecto: difusión, resignificación, dinamizador microeconómico, viabilidad económica y sustentabilidad; y que ofrezca la posibilidad de adopción en otras áreas de interés en la provincia.

Una vez completadas las etapas de prospección, de evaluación del impacto, de monitoreo, de control de relevancia y de solvencia del proyecto de Arqueoturismo, podrían agregarse otros sitios, o parte de ellos, a los originalmente propuestos, en tanto y en cuanto se demuestre su necesidad y pertinencia.

Sin pretender abarcar con esto la totalidad del tema, vemos oportuno señalar aquí, a través de esta propuesta de Turismo Arqueológico, la necesidad imperiosa te hacer algo concreto en relación a la protección y difusión del patrimonio arqueológico del país. Como sostiene Rex González: "Es necesario que quede bien en claro la relación que existe entre la defensa del patrimonio y la investigación científica en arqueología: si destruimos los sitios arqueológicos de nada vale que formemos los mejores arqueólogos del mundo. La mejor formación académica se esteriliza si se carece de los datos, de la base empírica para una investigación o para el conocimiento ulterior, como es la que proporciona un yacimiento arqueológico". (González, 1989:112).

La arqueología sin objeto de estudio no existe; y una de las partes integrantes de su objeto, sin duda la más significativa, son los sitios arqueológicos. En el contexto de este trabajo, resaltar la importancia de la preservación del sitio no es un anacronismo fruto de la herencia del empirismo o de la tradición histórico-cultural. Es sólo un intento por señalar lo que consideramos un olvido en el desarrollo de nuestra disciplina, la cual ha desbalanceado sus esfuerzos entre la investigación metodológico-procesual versus la investigación en el 
campo de la conservación y la difusión, retomando de alguna manera la vieja herencia positivista que caracterizó los comienzos de la arqueología: "Los inicios de la arqueología argentina fueron de raíz positivista; la ciencia por la ciencia misma, los que escindieron a nuestra disciplina de los problemas sociales, de la historia..." (González, 1989:113).

Reconocer y difundir la importancia de la conservación del patrimonio puertas dentro y fuera de nuestra disciplina, es tarea de todos, pero no para el futuro sino para el ayer. Comenzar por reconocer estos problemas es sólo el primer paso, pero quizás el menos importante, si no es acompañado por la transformación del accionar de cada uno de nosotros.

Agradecimientos:

El siguiente trabajo es el desarrollo de un ensayo anterior (1997a) denominado "Turismo Arqueológico en el NOA: Una Propuesta de Desarrollo Sustentable". Agradezco la lectura y comentarios hechos sobre aquél a Patricia Monsalve, Alicia Tapia, Lidia García, Daniel Olivera y José A. Pérez.

Notas:

1. Si bien el presente trabajo reconoce como marco de aplicación el contexto histórico, social y económico de la República Argentina, en su porción Noroeste perteneciente al Área Andina, es indudable que cada uno de los colegas que analicen estas líneas encontrarán similitudes con sus experiencias de trabajo en sus propios contextos sociopolíticos.

2. Al respecto; se puede consultar Berberián, 1992; Tarragó y Piñeiro, 1995.

\section{BIBLIOGRAFÍA}

BERBERIÁN,EduardoE.

1992 Laprotección jurídica del patrimonio arqueológico en la República Argentina. Ed. Comechingonia. Córdoba.

BONFIL B., Guillermo

1994 "Nuestro patrimonio cultural: un laberinto de significados". En: Memoria del Simposio "Patrimonio y Política Cultural para el Siglo $X X I "$, pp. 17-34. Coordinado por J.Cama Villafranca y R. Witker Bara. Editorial INAH. México.

CARVAJAL, Julio E.

1992 La cara oculta del viajero. Reflexiones sobre antropología y turismo. Editorial Biblos. Buenos Aires.
CHAMPIN, Christophe

199 "Informática contra tráfico". En: Fuentes UNESCO. No. 83, octubre.

DELFINO, Daniel D. y Pablo Gustavo RODRfGUEZ

1989 "Sobre las nociones de patrimonio y administración de recursos culturales. Análisis de sus implicancias y las condiciones previas para una propuesta alternativa". En: El Uso del Pasado. Mesa Legislación, pp.19-32. Facultad de Ciencias Naturales y Museo Universidad Nacional de La Plata.

\section{DE MATTOS, Carlos A.}

1996 "Modelos de crecimiento económico endógeno y divergencia interregional, ¿nuevos caminos para la gestión regional?". En: Documentos del Instituto, Serie Azul, Instituto de Estudios Úrbanos, No. 11, diciembre, pp. 1-22. Ed. PUC. Chile.

\section{El Mensajero Turístico}

1997 "De compras por la Argentina". En: El Mensajero Turístico. Año VI, $\mathrm{N}^{\circ} 305,28$ de Abril, pp. 32-33. Ed. Comunicaciones Turísticas.

\section{GARCĹA C., Néstor}

1989 "La Política Cultural en Países en Vías de Desarrollo". En: Antropología y Políticas Culturales. Patrimonio e Identidad, pp. 7 a 28. Ed. por Rita Ceballos. Buenos Aires.

\section{GLIGO, Nicolo}

1987 "Política, sustentabilidad ambiental y evaluación patrimonial". En: Pensamiento lberoamericano. No.12, julio-diciembre, pp.23 a 39 . Madrid.

\section{GONZÁLEZ, Alberto Rex}

1954 "Las ruinas de Loma Rica y alrededores". En: Natura, Tomo 1, No. 1, pp. 75 a 94. Ministerio de Agricultura y Ganadería de la Nación. Administración General de Parques Nacionales.

1984 Rescate arqueológico en Argentina. Estado Actual y Sugerencias. Informe para la "Second New World Conference on Rescue Archaeology". Dallas, Texas. 15-17 de noviembre de 1984. Mecanografiado, 18p.

1989 "El patrimonio cultural y la investigación en arqueología". En: Antropología y Políticas Culturales. Patrimonio e Identidad, pp. 111 a 117. Ed. por Rita Ceballos. Buenos Aires.

1991 "El país de nomeacuerdo. La situación del patrimonio cultural en la Argentina. Mesa Redonda". En: Ciencia Hoy, Vol. 3, No. 16, Noviembre, pp.33. Buenos Aires. 
KAN, Sandra

1995 "Ruinas de la discordia". En: Report, 18 de diciembre, pp. 28-29. Ed. Impresiones Newgate S.A. Buenos Aires.

LUCKAS, Robert

1988 "On the Mechanics of Economic Development". En: Journal of Monetary Economics, No. 22, Julio. University of Chicago. Chicago.

\section{LUMBRERAS, Luis Guillermo}

1989 "La Cuestión del Patrimonio Cultural en las Condiciones Pluriculturales de origen Colonial: El caso de Penú". En: Antropología y Políticas Culturales. Patrimonio e Identidad, pp. 5364. Editado por Rita Ceballos. Buenos Aires.

MADRAZZO, Guillermo B.

1989 "Políticas Culturales y Compromiso Cientifico". En: Antropología y Políticas Culturales. Patrimonio e Identidad, páginas 101 a 110. Editado por Rita Ceballos. Buenos Aires.

MAGADÁN, MarceloL.

1988 "Iglesia de Santa María: a Dios rogando y con la maza dando. La campaña de modernización en los Valles Calchaquíes". En: Diario Página 12, 22 de junio, p. 23. Buenos Aires.

MARINI, Carlos Flores

1973 "Revitalización urbana y desenvolvimiento turístico". En: Boletín del Centro de Investigaciones Históricas y Estéticas. No. 6, pp. 149 a 152. Caracas.

OEA

1973a "Las Normas de Quito". En: Boletín del Centro de Investigaciones Históricas y Estéticas. No. 6. pp. 249 a 266. Caracas.

1973b "Reunión sobre identificación, protección y vigilancia del patrimonio arqueológico, histórico y artístico". En: Boletín del Centro de Investigaciones Históricas y Estéticas. No. 6, pp. 225 a 233. Caracas.

RALLI, Marra

1996 "En busca de un culpable". En: El Mensajero Turístico. Año V, No. 273, pp. 22 a 23. Ed. Comunicaciones Turísticas.

PÉREZGOLLÁN, José A.

1989 "La Duda es la Jactancia de los Antropólogos". En: Antropología y Políticas Culturales. Patrimonio eldentidad, pp. 111 a 117. Editado por Rita Ceballos. Buenos Aires.
1991 "El país de nomeacuerdo. La situación del patrimonio cultural en la Argentina. Mesa Redonda". En: Ciencia Hoy, Vol. 3, No. 16, Noviembre, p. 32. Buenos Aires.

\section{REPORT}

1995a "La preferida de Ramsés". En: Report, 13 de noviembre, p. 14. Ed. Impresiones Newgate S.A. Buenos Aires.

1995b "Egipto: Puente conflictivo". En: Report, 12 de diciembre, p. 12. Ed. Impresiones Newgate S.A. Buenos Aires.

1997 "El NOA se organiza". En: Report, 12 de mayo, p. 26. Ed. Impresiones Newgate S.A. Buenos Aires.

\section{ROSAS MANTECÓN, Ana María}

1994 “ ¿Qué es el patrimonio cultural y por qué defenderlo?". En: Memoria del Simposio "Patrimonio y Política Cultural para el Siglo XXI", pp. 35 a 42. Coordinado por J. Cama Villafranca y R. Witker Barra. Ed. INAH. México.

\section{SCHÁVEL ZON, Daniel}

1989 "La restauración de arquitectura prehispánica en la Argentina. Notas para su historia". En: Runa XIX (1989-90), páginas 83 a 93. Buenos Aires.

1990 La conservación del patrimonio cultural en América Latina. Instituto de Arte Americano e Investigaciones Estéticas Mario BuschiazzoThe Getty Grant Program, Universidad de Buenos Aires. Ed. Compañía Impresora Argentina. S.A. Buenos Aires.

SOSA, Jorge A.

1997a "Turismo Arqueológico en el NOA: Una Propuesta de Desarrollo Sustentable". En: Noticias en Antropología y Arqueología. Sección: Defensa del Patrimonio Cultural, p. 20. Revista Electrónica de Difusión Científica. Buenos Aires.

1997b Base de Datos del Patrimonio Arqueológico: Una propuesta para el registro de sitios arqueológicos (ms.).

TARRAGO, Myriam Noemi y Mónica PIÑEIRO

1995 "La práctica de la arqueología en Argentina". En: Revista de Arqueología Americana. No. 9, Julio-Diciembre, pp. 167 a 188. Instituto Panamericano de Geograffa e Historia. Costa Rica.

\section{VIAEEROVIP}

1995 "El retorno de las momias... a las vitrinas museísticas". En: Viajero VIP, Octubre, p. 6. Guayaquil. Ecuador. 